\title{
Electrophysiological biomarkers of central nervous system affection in cases of chronic obstructive pulmonary disease (COPD)
}

\author{
Hossam Abd El Monem Ali ${ }^{1}$ and Ahmed Salama Al-Adl ${ }^{2^{*}}$ (D)
}

\begin{abstract}
Background: Chronic obstructive pulmonary disease is associated with significant systemic abnormalities which includes systemic inflammation and neurohormonal activation that are considered the main mechanisms of the pathophysiology in systemic involvement. The aim of the present study was to detect the subclinical affection of the central nervous system in patients with stable chronic obstructive pulmonary disease.

Results: Forty patients with chronic obstructive pulmonary disease were enrolled in this study and 30 healthy subjects as a control group. All patients and healthy subjects were submitted to full history taking, clinical examination, arterial blood gases, spirometry, evoked potential, and electroencephalogram. Regarding to brain stem auditory evoked potentials, there was a statistically significant increase of latency of waves numbers $\mathrm{I}, \mathrm{III}$, and $\mathrm{V}$, and a statistically significant increase of interpeak latencies I-III in the COPD group when compared to the control group. On the other hand, there was a statistically significant decrease of brain stem auditory evoked potential I and $V$ amplitudes on both sides in the COPD group when compared to the control group. In visual evoked potential, there was a statistically significant increase of latency and decrease of amplitude of P100. In addition, there was a statistically significant increase of electroencephalogram changes in the COPD group when compared to the control group ( $20.0 \%$ vs. $3.3 \%$, respectively).
\end{abstract}

Conclusion: In patients with chronic obstructive pulmonary disease, the central nervous system could be affected subclinically as the severity of chronic obstructive pulmonary disease increased, and the patient should be electrophysiologically monitored for early detection of nervous system affection.

Keywords: Chronic pulmonary disease, Visual evoked potential, Auditory evoked potential, Electroencephalography

\section{Background}

COPD is a chronic inflammatory lung disease, characterized by progressive lung tissue damage, shortness of breath, long-lasting coughing, and mucus production [1].

COPD is the fourth leading cause of death worldwide and an additional rise in the occurrence as well as the mortality of the disease is predicted for coming periods.

\footnotetext{
*Correspondence: salama139@yahoo.com; salama139@azhar.edu.eg IInternal Medicine Department, Faculty of Medicine, Al-Azhar University, Damietta, Egypt

Full list of author information is available at the end of the article
}

Therefore, there is an impending need to create awareness regarding COPD complication(s) [2]. It is well known that COPD is associated with significant systemic abnormalities [3]. Hypoxemia, hypercapnia, systemic inflammation, and neurohormonal activation are the main mechanisms of the pathophysiology in systemic involvement [4]. Numerous neurological involvements such as cerebrovascular diseases, polyneuropathies, motor neuron diseases, and cognitive impairment have been reported in patients with COPD [5-7]. The aim of the current study was to detect the subclinical affection of 
the central nervous system of patients with stable COPD.

\section{Methods}

This study was designed as a case-control study, conducted on 40 patients with COPD and 30 age- and sexmatched nonsmoker, healthy subjects free from chest, and neurological symptoms, considered as a control group, the study was conducted at neurology, internal medicine, and chest departments, Al-Azhar University Hospital, New Damietta, Egypt.

\section{Inclusion criteria}

Inclusion criteria include patients diagnosed as COPD, according to the global initiative for chronic obstructive pulmonary disease (GOLD) criteria [8].

\section{Exclusion criteria}

Exclusion criteria include the following: (1) patients who had diabetes mellitus, stroke, demyelinating disease, chronic liver disease, chronic renal failure, and chronic alcoholism, neurotoxic drug use; (2) patients with auditory problems as detected on the detailed history and clinical examination, which interfere with brain stem auditory evoked potential (like cerebellopontine angle lesions, brainstem stroke, multiple sclerosis, or hearing loss); and (3) patients with concomitant visual impairment as detected on the detailed history and clinical examination, which interfere with visual-evoked potential (like cataract, glaucoma, vitreous opacities, marked visual impairment, multiple sclerosis, or any cerebral causes affecting the visual pathway).

All included subjects were submitted to the following: (1) complete history taking: with special emphasis on the main complaint, age, sex, smoking habits, duration of disease, risk factors (occupation, pollution, residential area), history of other systemic diseases; (2) clinical and neurological examination; (3) arterial blood gases: $\mathrm{pH}$, partial arterial oxygen tension, partial arterial carbon dioxide tension and oxygen saturation were measured in arterial blood sample, at room air; (4) spirometric tests, and (5) neurophysiological assessment includes evoked potentials and electroencephalogram (EEG).

\section{Spirometric tests}

All patients underwent spirometry following the administration of $400 \mu \mathrm{g}$ of salbutamol while the patient was stable; forced vital capacity (FVC), forced expiratory volume in one second (FEV1), and FEV1/FVC ratio were measured. Spirometric studies were conducted in accordance with the American Thoracic Society as follows [9]: (a) explanation of the procedure to the patient carefully; (b) making sure that the patient was standing or sitting erect with feet firmly on the floor; (c) applying a nasal clip to the patient's nose; (d) urging the patient to breathe in fully; (e) sealing the lips of the patient around the mouthpiece; (f) asking the patient to blast air out as fast and as far as he can until the lungs were completely empty; $(\mathrm{g})$ asking the patient to breathe again as forcibly and fully as possible; and (h) at least three technically accepted maneuvers were done [10]. Spirometric parameters were measured to confirm the diagnosis and to assess the severity of COPD by using GOLD criteria, which classify patients with COPD into 4 stages according to the value of FEV1. Mild COPD: FEV1/FVC $<0.70$ FEV1 $\geq 80 \%$ normal, moderate COPD: FEV1/FVC $<0.70$ FEV1 50 79\% normal, severe COPD: FEV1/FVC $<0.70$ FEV1 30-49\% normal, very severe case of COPD: FEV1/ FVC $<0.70 \mathrm{FEV} 1<30 \%$ normal or FEV1 $<50 \%$ predicted plus chronic respiratory failure.

\section{Evoked potentials which include auditory and visual evoked potentials}

Studies were conducted via Nihon Kohden machine, Model UT- 0800 J. Box BOARD (2CH) For JB-942BK, made in Japan. Subjects were informed to take shampoo and bath of the scalp and strictly oil free on the daytime of recording. Disc electrodes placed on the scalp by 10 20 standard system with a conductive gel.

\section{Auditory brainstem evoked potentials (ABR)}

The reference electrode was positioned on the vertex (CZ) and active electrode on the side of the mastoid on which side of the ear is stimulated. The ground electrode is connected on the forehead. Electrode impedance was checked. The amplifier that was on since the biological signals are very trivial. Automatic artifact rejection was used. Sweep velocity was $1 \mathrm{~ms}$. Click acoustic stimuli at a rate of 11 pulses per second at an intensity of $90 \mathrm{~dB}$ hearing level to the ear stimulated and masking sound of $40 \mathrm{~dB}$ in the non-stimulated ear was given through headphone supplied by Medicaid. Electrical activity had low cut filters hertz and high cut filters 10 hertz in order to avoid any electrostatic and electromagnetic interferences including the domestic switches. One thousand auditory click responses were summed and averaged and displayed. In addition, recording latencies of ABR waves I, II, III, IV, and V, together with interpeak latencies (IPLs) of I-III, I-V, and III-V, and amplitudes of waves I and $\mathrm{V}$ were measured from recordings [11].

\section{Visual evoked potential (VEP)}

The reference electrode was positioned on the vertex $(\mathrm{Cz})$ and active electrode on $\mathrm{Oz}$, which is the highest point on the occiput. The ground electrode was connected on the forehead. Electrode impedance was checked. The amplifier was on since the biological signals are very small. Automatic artifact rejection was 
used. VEPs record the electrical potentials that are produced by changing patterns in a monitor from the occipital cortex by using surface electrodes and amplifications. The most prominent component of VEP examination is the positive peak wave (P100) that develops at the 100th millisecond and is measured as a 100 -ms average in normal individuals. The most important finding demonstrating optic nerve demyelination is a prolongation of P100 latency. VEP recordings were performed with an analysis time of $500 \mathrm{~ms}$ and the sweep speed of $50 \mathrm{~ms}$. Low- and high-frequency filter settings were 1 and $100 \mathrm{~Hz}$, respectively. Throughout the testing, all patients were settled in a semi-darkened room, with the stimulus presented on a monitor $100 \mathrm{~cm}$ from the tested eye. The monitor has the appearance of a draft board in which black squares turn to white and white squares turn to black (pattern reversal) at a rate of one to two times per second. One of the eyes was covered, and the individual was requested to look at the fixation point [11].

\section{Interpretation of data from visual evoked potential}

Inspection of the normal VEP reveals three identifiable waveforms: N75, P100, and N145. The P100 is a positive potential at about $100 \mathrm{~ms}$ and is the only one used for VEP interpretation.

Brain stem auditory evoked potential interpretation of the data is as follows: the waves of interest are all convex and have the same multi-lobed appearance, the waves routinely analyzed in BAEP testing are numbered I through V. Waves I and V should be identified first. Wave I is approximately $2 \mathrm{~ms}$ after stimulus. Also, its only wave presents on ipsilateral but not contralateral record when recording also from a contralateral electrode derivation. Wave $\mathrm{V}$ normally appears at approximately $6 \mathrm{~ms}$ and is often combined with wave IV into a single complex waveform. Wave V is also the first waveform whose falling edge dips below the bassline [11].

\section{Electroencephalogram (EEG)}

Studies were conducted at air conditioned, quiet room via Analog EEG Neurofax machine; Model EEG - 7410 K. Made in japan. Procedures: A direct representation of the cerebral signal amplified many times to be displayed on paper. Surface electrodes are fixed to the skin by using electrode gel. Locate the positions for electrodes using the 10-20 Electrode Placement System. Electrode impedance should be at least $100 \mathrm{ohms}$ and no more than $5 \mathrm{k}$. Basic EEG rhythms, rhythm description normal: alpha $8-13 \mathrm{~Hz}$ posterior dominant rhythm in older children and adults. Beta $>13 \mathrm{~Hz}$ normal in sleep theta 4-7 Hz drowsiness and sleep delta $<4 \mathrm{~Hz}$ sleep, abnormal (epileptiform) activity consists of spikes that have a duration of less than $70 \mathrm{~ms}$, sharp waves that have a duration of 70-200 m, and slow waves that have a duration of more than $200 \mathrm{~m}$ [11]. Interpretation included normal or abnormal, how the recording is abnormal (focal or generalized), and which area was mostly affected in addition to the clinical implications of the finding; in our study, all EEG records were revised by the same interpreter of EEG.

\section{Statistical analysis}

The collected data were coded and statistically analyzed using SPSS program for Windows version 16 (SPSS Inc., USA). Parametric numerical data were expressed as mean and standard deviation (SD), while qualitative data were expressed as relative frequency $(n)$ and percent distribution. Independent sample $(t)$ Student's test was used for comparison between two means for parametric variables and Mann-Whitney $(U)$ test for non-parametric numerical variables; in addition, qualitative data were compared by chi-square test $\left(X^{2}\right)$. For the correlation between two parameters, Spearman's correlation coefficient $(r)$ was used. $P$ value $\leq 0.05$ was considered significant for the interpretation of results.

\section{Results}

The study was conducted on 40 patients with COPD and 30 healthy subjects and having the following characteristics: the mean age of the COPD group was $63.80 \pm$ 2.13 years, while the mean age of the control group was $64.13 \pm 1.94$ years. Male gender represented $85 \%$ of the COPD group and $70 \%$ of the control group, and there was no significant difference between both groups as regard either age or sex distribution. The mean-smoking pack per year in patients was 23.62 and SD was 14.5.

Regarding the Arterial Blood Gases and Pulmonary Function in studied groups there was a statistically significant decrease of So2 \% (90.5 Vs 94.8) and FEV1/ FVC (57 Vs 80.7) in COPD group when compared to control group (Table 1).

Table 1 Arterial blood gases and pulmonary function in the studied groups

\begin{tabular}{lllllll}
\hline & COPD & & & Control & \multicolumn{1}{c}{$\boldsymbol{P}$} \\
\cline { 2 - 3 } & Mean & SD & & Mean & SD & \\
\hline So2 \% & 90.57 & 1.87 & & 94.83 & 0.87 & $<0.001^{*}$ \\
PH & 7.32 & 0.04 & & 7.41 & 0.02 & $<0.001^{*}$ \\
PAO2 mmHg & 64.25 & 5.98 & 74.13 & 1.33 & $<0.001^{*}$ \\
PCO2 mmHg & 59.85 & 6.46 & & 41.2 & 2.05 & $<0.001^{*}$ \\
FEV1 \% & 57.75 & 15.13 & & 88.66 & 2.1 & $<0.001^{*}$ \\
FEV1 / FVC & 57 & 9.36 & & 80.76 & 2.69 & $<0.001^{*}$ \\
FVC\% & 1 & 0.18 & & 1.09 & 0.02 & $0.007^{*}$ \\
\hline
\end{tabular}

*Significant 
The severity of COPD, according to GOLD criteria, was grade I in 3 cases (7.5\%), grade II in 25 cases $(62.5 \%)$, grade III in 8 cases (20.0\%), and grade IV in 4 cases $(10.0 \%)$.

Regarding the brainstem auditory evoked potentials, there was a significant increase of latency of wave numbers I, III, and V on both sides and a significant increase of IPLs I-III on the right side in the COPD group when compared to the control group. On the other hand, there was a significant decrease of BAEP-I and V amplitudes on right and left sides in the COPD group when compared to the control group (Table 2).

In the number of cases with affected brain stem auditory evoked potentials, there was a significant affection of the COPD group compared to the control group (42.5 vs $10 \%$ ) (Table 3 ), where a variation of \pm 3 SD from the control values was accepted as abnormal.

Regarding the visual evoked potential (VEP), there was a significant increase of latency in 11 patients in the COPD group (27.5\%) and a decrease of amplitude in 3 patients in the COPD group $(7.5 \%)$ on both sides of P100 (Table 4).

There was a statistically significant increase in the number of cases affected in the COPD group compared

Table 2 Comparison between patient and control groups as regards the auditory brain stem evoked potential (ABR)

\begin{tabular}{|c|c|c|c|c|c|c|}
\hline & & \multicolumn{2}{|l|}{ COPD } & \multicolumn{2}{|c|}{ Control } & \multirow[t]{2}{*}{$P$} \\
\hline & & Mean & SD & Mean & SD & \\
\hline \multirow[t]{2}{*}{ I-Latency (ms) } & Right & 1.54 & 0.29 & 1.24 & 0.08 & $<0.001^{*}$ \\
\hline & Left & 1.61 & 0.31 & 1.28 & 0,09 & $<0.001^{*}$ \\
\hline \multirow[t]{2}{*}{ II-Latency (ms) } & Right & 2.63 & 0.31 & 2.57 & 0.15 & $0.28(\mathrm{NS})$ \\
\hline & Left & 2.74 & 0.26 & 2.68 & 0.11 & 0.22 (NS) \\
\hline \multirow{2}{*}{$\begin{array}{l}\text { III-Latency } \\
\text { (ms) }\end{array}$} & Right & 3.64 & 0.3 & 3.26 & 0.12 & $<0.001^{*}$ \\
\hline & Left & 3.64 & 0.27 & 3.3 & 0.09 & $<0.001^{*}$ \\
\hline \multirow{2}{*}{$\begin{array}{l}\text { IV-Latency } \\
\text { (ms) }\end{array}$} & Right & 4.56 & 0.05 & 4.54 & 0.06 & 0.31 (NS) \\
\hline & Left & 4.58 & 0.07 & 4.56 & 0.05 & 0.12 (NS) \\
\hline \multirow{2}{*}{$\begin{array}{l}\text { V-Latency } \\
\text { (ms) }\end{array}$} & Right & 5.88 & 0.27 & 5.45 & 0.11 & $<0.001^{*}$ \\
\hline & Left & 5.97 & 0.29 & 5.49 & 0.1 & $<0.001^{*}$ \\
\hline \multirow{2}{*}{$\begin{array}{l}\text { IPLs } \\
\text { |-III (ms) }\end{array}$} & Right & 2.1 & 0.13 & 2.01 & 0.13 & $0.01^{*}$ \\
\hline & Left & 2.02 & 0.25 & 2.02 & 0.12 & $0.8(\mathrm{NS})$ \\
\hline \multirow{2}{*}{$\begin{array}{l}\text { IPLs } \\
\text { I-V (ms) }\end{array}$} & Right & 4.33 & 0.35 & 4.21 & 0.17 & 0.08 (NS) \\
\hline & Left & 4.35 & 0.42 & 4.2 & 0.17 & 0.07 (NS) \\
\hline \multirow{2}{*}{$\begin{array}{l}\text { IPLs } \\
\text { III-V (ms) }\end{array}$} & Right & 2.23 & 0.38 & 2.19 & 0.16 & $0.6(\mathrm{NS})$ \\
\hline & Left & 2.32 & 0.36 & 2.2 & 0.15 & 0.06 (NS) \\
\hline \multirow[t]{2}{*}{ BAEP-I amplitude $(\mu \mathrm{v})$} & Right & 0.33 & 0.02 & 0.67 & 0.04 & $<0.001^{*}$ \\
\hline & Left & 0.34 & 0.03 & 0.68 & 0.04 & $<0.001^{*}$ \\
\hline \multirow[t]{2}{*}{ BAEP-V amplitude $(\mu v)$} & Right & 0.44 & 0.04 & 0.46 & 0.03 & $0.05^{*}$ \\
\hline & Left & 0.45 & 0.04 & 0.47 & 0.04 & $0.035^{*}$ \\
\hline
\end{tabular}

IPL interpeak latency difference, NS non-significant, *significant
Table 3 Comparison between patient and control groups as regards the number of cases with affected brainstem auditory evoked potentials

\begin{tabular}{lllllll}
\hline & COPD & & & \multicolumn{2}{c}{ Control } & P value \\
\cline { 2 - 3 } & $\boldsymbol{N}$ & $\%$ & & $\boldsymbol{N}$ & $\%$ & \\
\hline Normal & 23 & 57.5 & & 27 & 90 & $0.0012^{*}$ \\
Abnormal & 17 & 42.5 & & 3 & 10 & \\
\hline *significant & & & & & &
\end{tabular}

to the control group (35\% vs 3.3\%) as regards VEP (Table 5). where a variation of $\pm 3 \mathrm{SD}$ from the control values was accepted as abnormal.

Regarding EEG changes, there was a statistically significant increase in the number of cases affected in the COPD group when compared to the control group (20.0\% vs $3.3 \%$ respectively). Eight patients in the COPD group showed EEG changes: five of them have focal slow wave mostly at frontal and temporal regions, the other three patients showed generalized slowness, and one case in the control group showed focal slow wave at frontoparietal regions. No case of those with EEG changes had epileptic seizures (Table 6).

Concerning to the correlation between COPD severity and different evoked potential, in ABR, there was a positive, significant correlation between wave I latency on the right and left side; wave IV latency on the right side, and negative correlation with IPls I-III on the left, IPLs I-V on both right and left sides, and IPLs III-V on right and left side. In this study, there was a significant increase of BAEP affection with increased severity of COPD, while no significant increase of VEP affection with increased severity of COPD (Table 7).

\section{Discussion}

Our study was conducted on 40 patients with COPD, the mean age was $63.80 \pm 2.13$ year, 24 (85\%) of them was male gender and $6(15 \%)$ was female and 30 subjects as a control group with mean age $64.13 \pm 1.94$ years, 21 (70 $\%)$ of them was male gender and 9 (30\%) was female, and there was no statistically significant difference between both groups concerning either age or sex distribution. On the other hand, smoking packs/year was significantly higher in COPD when compared to the

Table 4 Comparison between patient and control groups as regards the visual evoked potential (VEP)

\begin{tabular}{|c|c|c|c|c|c|c|}
\hline & & \multicolumn{2}{|l|}{ COPD } & \multicolumn{2}{|c|}{ Control } & \multirow[t]{2}{*}{$P$} \\
\hline & & Mean & SD & Mean & SD & \\
\hline \multirow[t]{2}{*}{ Right P100 } & Latency (ms) & 107.9 & 8.1 & 95.36 & 3,45 & $0.005^{*}$ \\
\hline & Amplitude $(\mu v)$ & 4.39 & 0.63 & 4.95 & 0.32 & $<0.001^{*}$ \\
\hline \multirow[t]{2}{*}{ Left P100 } & Latency (ms) & 109.27 & 6.49 & 95.8 & 1.88 & $0.006^{*}$ \\
\hline & Amplitude $(\mu v)$ & 4.39 & 0.69 & 5.03 & 0.33 & $<0.001^{*}$ \\
\hline
\end{tabular}

*significant 
Table 5 Comparison between patient and control groups as regards the number of cases with affected brainstem auditory evoked potentials

\begin{tabular}{lllllll}
\hline & COPD & & & \multicolumn{2}{c}{ Control } & P value \\
\cline { 2 - 3 } & $\mathbf{N}$ & \% & & $\boldsymbol{N}$ & $\%$ & \\
\hline Normal & 26 & 65 & & 29 & 96.7 & $0.0012^{*}$ \\
Abnormal & 14 & 35 & & 1 & 3.3 & \\
\hline *significant & & & & &
\end{tabular}

control group ( $23.62 \pm 14.50$ vs $0.00 \pm 0.00$, respectively). In the present work, results of arterial blood gases revealed a significant decrease of $\mathrm{SO} 2, \mathrm{pH}$, and $\mathrm{PaO} 2$ in the COPD group when compared to the control group. However, there was a significant increase of PCO2 in the COPD group when compared to the control group ( $59.85 \pm 6.46$ vs $41.40 \pm 2.11$, respectively).

In the present work, results of pulmonary function tests revealed a significant decrease of FEV1, FEV1/FVC, and $\mathrm{FVC} \%$ in the COPD group when compared to the control group. These results are comparable to those reported by Calik- Kutukcu et al. 2014 [12] who reported that FVC, FEV1, FEV1/FVC, FEF25-75\%, and PEF values of patients were significantly lower than those of healthy subjects $(p=0.001)$.

The severity of COPD, according to the Global Initiative for Chronic Obstructive Lung Disease (GOLD) criteria mild (grade I) in 3 cases $(7.5 \%)$, moderate (grade II) in 25 cases (62.5\%), severe (grade III) in 8 cases $(20.0 \%)$, and very severe (grade IV) in 4 cases (10.0\%). Also, Calik-Kutukcu et al. [12] reported that, according to the Global Initiative for Chronic Obstructive Lung Disease (GOLD) criteria, $5 \%$ of patients had mild, $45 \%$ moderate, $30 \%$ severe, and $20 \%$ very severe.

In addition, Karthikkeyan et al. [13] reported that the severity of mild, moderate type-IIA, and moderate typeIIB forms of the disease were found to occur in 17, 63, and $20 \%$, respectively, in the sample population. These results are comparable to the present study.

Chronic hypoxia in patients with COPD has been proposed as the most important cause of CNS involvement [14]. In Kayacan et al.'s [14] study, statistically significant correlations were confirmed between brain-stem auditory evoked response and pulmonary function test and

Table 6 EEG results in the studied group

\begin{tabular}{|c|c|c|c|c|c|c|c|}
\hline & & & \multicolumn{2}{|c|}{ COPD } & \multicolumn{2}{|c|}{ Control } & \multirow[t]{2}{*}{$P$ value } \\
\hline & & & $N$ & $\%$ & $N$ & $\%$ & \\
\hline \multirow[t]{4}{*}{$\mathrm{EEG}$} & Normal & & 32 & 80 & 29 & 96.67 & $0.039 *$ \\
\hline & Abnormal & Total & 8 & 20 & 1 & 3.3 & \\
\hline & & Focal & 5 & 62.5 & 1 & 100 & \\
\hline & & Geralizied & 3 & 37.5 & 0 & 0 & \\
\hline
\end{tabular}

*significant
Table 7 Correlation between COPD severity and evoked potentials (visual and auditory)

\begin{tabular}{|c|c|c|c|}
\hline & & GOLD & \\
\hline & & $R$ & $P$ value \\
\hline BAEP I latency & Right & 0.93 & $<0.001^{*}$ \\
\hline & Left & 0.94 & $<0.001^{*}$ \\
\hline BAEP \|l latency & Right & 0.3 & 0.06 (NS) \\
\hline & Left & 0.26 & 0.10 (NS) \\
\hline BAEP III latency & Right & 0.92 & $<0.001^{*}$ \\
\hline & Left & 0.65 & $<0.001^{*}$ \\
\hline BAEP IV latency & Right & 0.38 & 0.016 \\
\hline & Left & 0.24 & 0.12 (NS) \\
\hline BAEP V latency & Right & 0.16 & $0.33(\mathrm{NS})$ \\
\hline & Left & -0.07 & $0.68(N S)$ \\
\hline IPL |-III & Right & 0.01 & $0.93(N S)$ \\
\hline & Left & $-0.49^{*}$ & $0.001^{*}$ \\
\hline IPL I-V & Right & -0.66 & $<0.001^{*}$ \\
\hline & Left & $-0.75^{*}$ & $<0.001^{*}$ \\
\hline IPL III-IV & Right & -0.62 & $<0.001^{*}$ \\
\hline & Left & -0.54 & $<0.001^{*}$ \\
\hline BEAP I amplitude & Right & 0.001 & 0.99 (NS) \\
\hline & Left & -0.07 & $0.68(N S)$ \\
\hline BEAP $\vee$ amplitude & Right & -0.12 & $0.47(N S)$ \\
\hline & Left & 0.13 & 0.42 (NS) \\
\hline P100 right & Latency & 0.12 & 0.44 (NS) \\
\hline & Amplitude & 0.10 & 0.54 (NS) \\
\hline P100 left & Latency & 0.09 & $0.58(\mathrm{NS})$ \\
\hline & Amplitude & 0.10 & $0.55(\mathrm{NS})$ \\
\hline
\end{tabular}

blood-gas parameters. However, a correlation was found with acidosis and hypercarbia in blood-gas analysis [15].

Concerning brain stem auditory evoked potentials, there was a statistically significant increase of latency of wave numbers I, III, and V on the right and left sides, and a statistically significant increase of IPLs I-III on the right side in the COPD group when compared to the control group. On the other hand, there was a statistically significant decrease of BAEP-I and V amplitudes on the right and left sides in the COPD group when compared to the control group. These results are comparable to those reported by Gupta et al. [16] who reported that, on the left ear, the latencies of waves I, III, and $\mathrm{V}$ in patients with COPD were prolonged significantly as compared to the healthy persons. The latencies of waves II and IV were also increased in the COPD group. Over the right side, there was significant prolongation of the latencies of waves III, IV, and V in the COPD group when compared to the healthy persons. The interpeak latencies (IPLs) of III-V and I-V were 
significantly prolonged in cases of COPD as compared to healthy persons over both ears; furthermore, interpeak latency of I-III was significantly prolonged in the COPD group over the right ear. The amplitude of the wave I-Ia in cases with COPD was significantly decreased when compared to that in healthy volunteers, over both ears respectively. Also, the amplitude of the wave $\mathrm{V}-\mathrm{Va}$ in patients with COPD was significantly decreased when compared with that in healthy persons, over both ears respectively.

In addition, Atis et al. [17] reported that BAEP were abnormal in $16(76.1 \%)$ of 21 cases; the most recorded abnormalities were prolonged wave I peak latency, prolonged wave V peak latency, and increased III-V IPL. An additional protruding abnormality was low wave I peak amplitude. In addition, there was a significant difference in the central transmission times between the patient and the control groups $(P<0.05)$. However, the rate of abnormalities reported in this study is very high and this may be explained by the inclusion of cases with severe COPD in the study.

Furthermore, Shalabi et al. [18] stated that, over the left ear, the latencies of waves I, II, III, and IV were significantly increased in patients with COPD. Over the right ear, the latencies of waves I, II, III, IV and V were significantly increased in patients with COPD. The interpeak latencies (IPLs) of I-III, I-V, and III-V together with the amplitude of the waves I-Ia and V-Va were significantly dissimilar in patients with COPD on both left and right ears. In addition, the number and percentage of patients with COPD the brain-stem auditory evoked potentials abnormalities were more predominant among very severe cases with COPD on both left and right ears, as reported in this work. Also, ElKady et al. [19] reported a statistically significant difference for all audio-logical measures between the control group and patients with COPD.

It has been assumed that the abnormal BAEP findings are due to brainstem hypoxia, which increases with the severity of COPD. It had been demonstrated that depression of the auditory nerve-brainstem evoked response, as well as vestibular and VEP during severe hypoxemia. In addition to chronic hypoxemia and hypercapnia, other associated factors in cases with COPD, are included such as tobacco smoking, malnutrition, and medications used in COPD treatment, for example, long-acting inhaled $\beta 2$ agonists, inhaled anticholinergic agents, inhaled glucocorticoids, and sustained-release theophylline, may be linked with neuropathy seen in patients with COPD [20].

On the other hand, Barbieri et al. [21] described that there was no significant difference in BAEP in mild or moderate chronic respiratory insufficiency away from acidosis. In addition, Nakano et al. [22] studied evoked potentials in patients with chronic respiratory insufficiency but did not discover any significant differences in BAEP parameters between patients and controls.

The possible explanation for this contradiction may be attributed to the use of the more detailed BAEP parameters in the present study compared with Nakano's study [22], in which only wave I and I-V IPL were estimated.

In our study, BAEP abnormalities were prolonged wave I peak latencies, and low wave I peak amplitude, which represents the function of the peripheral field of the cochlear nerve. These findings suggested that cranial neuropathy may be common in patients with COPD. Another abnormality in our study was increased III-V IPL, which proposes the presence of CNS involvement at the upper brainstem level, as reported by Chiappa [23]. However, the difference between COPD and control groups was statistically non-significant.

Regarding VEP, there was a significant increase of latency and decrease of amplitude on both the right and left sides of P100. These results going in accordance with Karthikkeyan et al. [13] who reported that the latencies measured in response to stimulus were found to be prolonged highly significantly $(P<0.01)$ in patients with COPD than controls. While there was a highly significant $(P<0.01)$ fall in the amplitude $(P 100)$ in patients with COPD. In addition, they found a positive correlation between disease severity and visual evoked potential. However, in the present study, we could not find such a correlation. In addition, Mikaeili et al. [24] reported that mean P100 latency in both eyes was significantly longer in patients with COPD when compared to healthy, nonsmoker controls. The significant increase in latency in patients with COPD may be attributed to synaptic delay or altered neuronal processing in the optic nerve which is in accordance with the suggestion of Gupta et al. [16].

In the present work, the P100 latency is the most consistent one having the least variable peak. The latency of P100 in patients with COPD was prolonged than normal individuals in left and right eyes respectively, with a highly significant probability value $(P<0.01)$. This finding is in agree with the studies by Demir et al. [25] and Singh et al. [26]. Sezer et al. [27] also showed that P100 value was altered in patients with COPD and further assumed that the elevations in latencies of $\mathrm{P}$ waves were brought about by the hypoxia, hypercapnea, and acidosis, resulting from COPD.

The amplitudes of P100 were highly significantly reduced in the COPD group, indicates the influence of COPD on VEP measurements, which agrees with the studies by Ozge et al. [28], Sohmer et al. [29], and Gunn et al. [30]. This reduction is attributed to hypoxemia and acidosis resulting in optic nerve damage by harming 
vasa-nervosum that leads to neuronal hyperpolarization and decreased excitability. On the opposing, this parameter was unaltered in patients with COPD as reported by Gupta et al. [16]. and Demir et al. [25].

Regarding to EEG changes, there was a significant increase in the COPD group when compared to the control group (20.0\% vs $3.3 \%$, respectively). No case of those with EEG changes had epileptic seizures, 8 patients from the COPD group have EEG changes, five of them have focal EEG changes and three have generalized EEG changes. One of the 30 control subjects had focal EEG changes. Ozge et al. [28] reported five patients (from 54 patients with severe COPD) in the COPD group 9.25\% and one from 24 in the control group $4.1 \%$ showed a specific frontotemporal slow wave pattern on EEG, especially in the left cerebral hemisphere; however, none had epileptiform EEG abnormalities and significant amplitude asymmetry. Also, John et al. [31] described that the presence of slow waves in frontal EEG leads, the proportion of patients with abnormal cognitive scores were increasing and related to increased severity of COPD but not statistically significant.

In contrast, Bernhard et al., [32] reported that although patients with COPD often complain of fatigue and cognitive disturbances, they did not find a change in the EEG band distribution in their patient group.

\section{Conclusion}

In patients with COPD, the central nervous system could be affected subclinically as the severity of COPD increased and the patients should be electrophysiologically monitored for early detection of nervous system affection.

\section{Abbreviations}

COPD: Chronic obstructive pulmonary disease; GOLD: Global Initiative for Chronic Obstructive Lung Disease; VEP: Visual evoked potential;

EEG: Electroencephalogram; BAEP: Brainstem auditory evoked potential

\section{Acknowledgements}

Not applicable

\section{Authors' contributions}

HA contributed to the research idea, methodology, data collection, analysis and data interpretations, general supervision of the research group, writing of the manuscript, and drafting and revising the manuscript. AS contributed to the data collection, data analysis, data interpretations, writing of the manuscript, and drafting and revising the manuscript. The authors read and approved the final manuscript.

\section{Funding}

No funding sources for this research had been declared (financial or nonfinancial). Funding was provided by the researchers.

\section{Availability of data and materials}

Findings on which the conclusions of the manuscript rely are summarized in the manuscript. For further inquiries, please contact the corresponding author.

\section{Declarations}

\section{Ethics approval and consent to participate}

The study was approved by the local Ethics committee of Damietta faculty of medicine Al-Azhar University. Registration Number: IRB 00012367 - 18-12003. Issuing: 25 Dec 2018, Expiration Date: valid until 24 Dec 2021, Damietta faculty of medicine IRB, Al-Azhar University. Before participation in the study, the study procedure was clarified for each subject, and verbal consent was provided by each person of the participants and was approved by the ethical committee as the study procedure do not interfere with any medical conditions and no effects on the health of participants.

\section{Consent for publication}

Not applicable.

\section{Competing interests}

The authors declare that they have no competing interests.

\section{Author details}

${ }^{1}$ Neurology Department, Faculty of Medicine, Al-Azhar University, Damietta, Egypt. ${ }^{2}$ Internal Medicine Department, Faculty of Medicine, Al-Azhar

University, Damietta, Egypt.

Received: 18 December 2020 Accepted: 25 April 2021

Published online: 14 June 2021

\section{References}

1. Jiang Z, Zhu L. Update on molecular mechanisms of corticosteroid resistance in chronic obstructive pulmonary disease. Pulm Pharmacol Ther 2016:37:1-8.

2. Kazi K, Mehta A, Mulla M. Electrophysiological evaluation of peripheral nerves in patients with COPD. IJBAP. 2012;1 (1):83-7.

3. Tkác J, Man SF, Sin DD. Systemic consequences of COPD. Ther Adv Respir Dis. 2007;1:47-59.

4. Van Gestel AJ, Steier J. Autonomic dysfunction in patients with COPD. J Thorac Dis. 2010;2:215-22.

5. Doehner W, Haeusler KG, Lainscak M. Neurological and endocrinological disorders: orphans in COPD. Respir Med. 2011;105(Suppl 1):S12-9.

6. Kirkil G, Tug T, Muz MH. The evaluation of cognitive functions with P300 test for COPD patients in attack and stable period. Clin Neurol Neurosurg. 2007:109:553-60.

7. Agrawal D, Vohra R, Gupta P. Subclinical peripheral neuropathy in stable middle-aged patients with COPD. Singapore Med J. 2007;48(10):887.

8. Global Initiative for Chronic Obstructive Lung Disease (GOLD) (2014): Global strategy for the diagnosis, management and prevention of COPD; 2014. Available at: http://www.goldcopd.org. Accessed 4 Feb 2015

9. American thoracic society. Standard for the diagnosis and care of patients with COPD. Am J Respir Crit Care Med. 1995;152:S77-121.

10. American Thoracic Society, European Respiratory Society. American Thoracic Society/European Respiratory Society statement: standards for the diagnosis and management of individuals with alpha-1 antitrypsin deficiency. Am J Respir Crit Care Med. 2003;168:818.

11. Karl E. Misulis and Thomas C. Head. Brainstem auditory evoked potentials, Visual evoked potentials. Part II: Electroencephalography. In: Karl E. Misulis and Thomas C. Essential of clinical neurophysiology; 3rd edition. Garland Science; 2003.191-208, 37-83.

12. Calik-Kutukcu E, Savci S, Saglam M. A comparison of muscle strength and endurance, exercise capacity, and fatigue in patients with COPD and healthy subjects: a cross-sectional study. BMC Pulmon Med. 2014:14:6-13.

13. Karthikkeyan K, Padma K, Rao VB. Evaluation of Visual Evoked Potential in Patients with COPD. Indian J Physiol Pharmacol. 2015;59(2):182-8.

14. Kayacan O, Beder S, Karnak D. Neurophysiological changes in COPD patients with chronic respiratory insufficiency. Acta Neurol Belg. 2001;101:160-5.

15. Ozge A, Atis S, Sevim S. Subclinical peripheral neuropathy associated with COPD. Electromyogr Clin Neurophysiol. 2001;41:185-91.

16. Gupta PP, Sood S, Agarwal D. Assessment of VEP in stable COPD patients with no visual impairment. Ann Thorac Med. 2010;5:222-7.

17. Atis S, Ozge A, Sevim S. The brainstem auditory evoked potential abnormalities in severe COPD. Respirology. 2001;6:225-9.

18. Shalabi N, Abdel El-Salam M, Abbas A. Brain-stem auditory evoked responses in COPD patients. Egypt J Chest Dis Tuberc. 2012;61:313-21. 
19. MA EK, Tawfik S, Durrant D. Study of auditory function in patients with COPD. Hear Res. 2006;212:109-16.

20. Liu D, Chen Q, Huang Z, Zhong J, Zhou L. Auditory brainstem response in severe obstructive sleep apnea-hypopnea syndrome children. Lin Chuang Er Bi Yan Hou Ke Za Zhi. 2005;19(19):868-70.

21. Barbieri S, Fayoumi Z, Berardinelli P. Evidence for a subclinical involvement of the central nervous system in mild or moderate chronic respiratory insufficiency. Electromyogr Clin Neurophysiol. 1996;36:67-72.

22. Nakano S, Imamura S, Hashimoto I. Evoked potentials in patients with chronic respiratory insufficiency. Intern Med. 1997;36:270-5.

23. Chiappa KA. Brainstem auditory evoked potentials: Methodology. In: Chiappa KA, editor. Evoked Potentials in Clinical Medicine. 3rd ed. USA: Lippincott-Raven Publishers; 1997. p. 157-98.

24. Mikaeili H, Yazdchi M, Sadeghi-Hokmabadi E. Correlation between optic nerve involvement and COPD. Clin Ophthalmol. 2015:9:271-4.

25. Demir HD, Inonu H, Etikan I. Evaluation of visual field parameters with COPD. Acta Ophthalmol. 2012;90:e349-54.

26. Singh SB, Thakur L, Anand JP. Changes in visual evoked potentials on acute induction to high altitude. Indian J Med Res. 2004;120:472-7.

27. Sezer M, Yaman M, Oruc S. Visual evoked potential changes in COPD. Eur Gen Med. 2007:4:115-8.

28. Ozge C, Ozge A, Unal O. Cognitive and functional deterioration in patients with severe COPD. Behav Neurol. 2006;17:121-30.

29. Sohmer H, Freeman S, Malachi S. Multi-modality evoked potentials in hypoxemia. Electroencephalogr Clin Neurophysiol. 1986;64:328-33.

30. Gunn AJ, Cook CJ, Gluckman PD. Electrophysiological responses of the fetus to hypoxia and asphyxia. J Dev Physiol. 1991;16:147-53.

31. John J, Venugopal P, Shaji CV. A study of electro encephalo graphic changes and cognitive functions in patients with chronic obstructive pulmonary disease with different grades of bode severity. Int I Contemp Med Res. 2016;3(11):3330-3.

32. Bernhard R, Melanie S, Stefan K. Neurovascular coupling and EEG band distribution in patients with chronic obstructive pulmonary disease. Int $J$ Clin Neurosci Ment Health. 2014;1:3.

\section{Publisher's Note}

Springer Nature remains neutral with regard to jurisdictional claims in published maps and institutional affiliations.

\section{Submit your manuscript to a SpringerOpen ${ }^{\circ}$ journal and benefit from:}

- Convenient online submission

- Rigorous peer review

- Open access: articles freely available online

- High visibility within the field

- Retaining the copyright to your article

Submit your next manuscript at $\boldsymbol{\nabla}$ springeropen.com 